\title{
The Modified Endothelial Cell-Derived Micro Particles in Endothelium Reparation
}

\author{
Alexander E. Berezin, Professor, MD, Ph.D. \\ Consultant of Therapeutic Unit, Private Hospital "Vita-Center", Zaporozhye, Ukraine \\ Consultant of Therapeutic Unit, Department of Internal Medicine, Medical University, Zaporozhye, Ukraine. \\ dr_berezin@mail.ru
}

Abstract: Growing evidence supports the hypothesis that endothelial cell-derived microparticles (MPs) might contribute to the pathogenesis of cardiovascular (CV) disease.Endothelial cell-derived MPs play a pivotal role in the regulation of the endogenous repair system, thrombosis, coagulation, inflammation, immunity and metabolic memory phenomenon. There is evidence that the MPs are secreted actively accompanied to other regulatory molecules. All these actively synthetizing and secreting factors include proteins, adhesion and intercellular signal molecules, peptides, lipids, free DNAs, microRNAs, and even microparticles (MPs) are defined as cellular secretome. The proteomic profile of secretome is under tightly control of genetic and epigenetic mechanisms, which may altered a secretion of the proteins involved into MPs' organization. Finally, this may contribute the modification of MP's after their secretion and throughout transfer to the target cells.As a result, communicative ability of endothelial cell-derived MPs may sufficiently worse.Subsequently,cross talk between some components of secretome might modulate delivering cargos of MPs and their regenerative and proliferative capabilities via intercellular signaling networks. The aim of the review is to discuss the effect of various components of secretome on MP-dependent effects on endothelium.

Keywords: endothelium; endothelial cells; secretome; reparation; microparticles.

\section{INTRODUCTION}

For last decade, elevated circulating level of microparticles(MPs) produced by various types of blood cells have been defined in the patients with established cardiovascular (CV) disease, as well as in individuals at higher risk of CV events and diseases [1-4].The endothelial damage occurring in CV disease is considered as an initial step to $\mathrm{CV}$ complications, as well as early stage of asymptomatic target organs damage irrespectively related to the $\mathrm{CV}$ mortality and morbidity.The ultimate goal is to identify useful diagnostic and predictive biomarkers and/or target tools in the vulnerable patientpopulation and diseased.

The current challenges in $\mathrm{CV}$ medicine have been addressing to improve of actual screening and predictive patients' platform.There is suggestive evidence that a number of circulating endothelial cell-derived MPs might be a clinically useful biomarker that pretty accurate predicts CV complications in general populations and patients with known CV disease [5-7].

Although an origin of endothelial cell-derived MPs from activated or apoptotic cells is crucial for realizing tissue repair, degenerative processes modulation, immune mediation, and directly / indirectly vascular injury [8], there are several controversies regarding an involvement of MPs in pathogenesis of CV disease [9-11]. The first controversy affects the pathophysiological properties of MPs. Indeed, the MPs secreted by activated endothelial cells may contribute to tissue reparation, restore endothelial function, mediate progenitor cell mobbing and differentiation, whereas apoptotic MPs are able directly injury endothelial cells and via a transfer of several proteins, active molecules, chromatin compounds including microRNAs and DNAs, regulate inflammation, 
coagulation, and immune response [12]. The next controversy relates a different presentation of endothelial cell-derived MPs in plasma of healthy individuals and changing of their numbers in various CV diseases and CV risks. Interestingly, circulating number of MPs originated from apoptotic endothelial cells increases in patients with CV risk factors, after newly CV events and in individuals with established CV disease. However, the ability of activated endothelial cells to active secret MPs progressively decreases depending on CV risk presentation, i.e. diabetes mellitus, abdominal obesity, insulin resistance, renal disease, and is due co-existing endothelial disintegrity [13-15]. Unfortunately, although there is strong association between circulating number of activated endothelial cell-derived MPs and CV risk, elevated level of apoptoticendothelial cell-derived MPs appears to be much more accurate predictive biomarker relating to CV death and CV diseases progression [16]. Else controversy is that the endothelial cell-derived MPsare constitutive biomarker of endothelial dysfunctionplaying a pivotal role in inflammation, vascular injury, angiogenesis, and thrombosis, but their predictive value on CV manifestation and progression is beyond severity of endothelial dysfunction. In fact, the imbalance between number of circulating endothelial cell-derived MPs distinguished their origin (activated or apoptotic endothelial cells) can be applied as more promising routine tests to improve CV risk prediction[17, 18].Whether "impaired phenotype" of endothelial cell-derived MPsas a causality factor contributed the vascular "competence" in $\mathrm{CV}$ disease is a predominantly pre-existing phenomenon associated with genetic / epigenetic performances or is resulting in various metabolic and age-dependent factors is not clear.There is a large body of evidence regarding that the biological abilities of EPCs are likely under posttranslational control of their secretome and that restore endothelial integrity after vascular injury by EPCs might relate to components of secretome, especially signature of MPs. Probably, variable effect of endothelial cell-derived MPs might relate to secretome particularities and the triggers, which induced cell mechanisms of synthesis and secretion of secretome. Major mechanisms involve secretome in the regulation of EPCsrecruitment, migration, differentiation, and release of proangiogenic factors are not fully investigated and require more explanations.

The aim of the review is to discuss the effect of various components of secretome on MP-dependent effects on endothelium.

\section{SECRETOME AND ITS COMPONENTS}

The variety spectrum of paracrine factors secreted by cells is due specific and non-specific triggers and exerted biological effects on target cells are determined secretome. By now, the secretome is considered a collection of factors consisting of transmembrane proteins and other components secreted by cells into the extracellular space. All these actively synthetizing and secreting factors include proteins, adhesion and intercellular signal molecules, peptides, lipids, free DNAs, microRNAs, and extracellular vesicles (i.e. exosomes and MPs).A significant portion (roughly 20\%) of the human secretome consists of secretory proteins incorporated into MPs. Interestingly, the proteomic profile of secretome is under tightly control of genetic and epigenetic mechanisms, which may altered a secretion of the proteins involved into MPs' organization. Finally, this may contribute the modification of MP's after their secretion and throughout transfer to the target cells. Although the innate mechanisms of alterations in the proteome of MPs with different origins are completely clear, the cellular secretome with preferential up- and -down regulationof broad spectrum of proteins (i.e. matricellularproteins, cell-cell adhesion molecules, procoagulants, growth factors) incorporated into MPs is considered a powerful trigger of tissue response to injury [19]. Indeed, the cell-to-MPs' cooperation is depended on presentation of the surface of the vesicles and target cells appropriate recognizing antigens, which interact with secreted proteins and consequently regulate in different manner the tissue response via switching specific transmembrane signal systems to nuclear transcriptional factors (i.e., NK-kB). Overall, the role of MPs as component of cell secretome with post -ranscriptionally modifiedregulatory activity are under wide discussion. Thus, mature endothelial cells and endothelial progenitor cells may communicate with each other by means of exchange of 
The Modified Endothelial Cell-Derived Micro Particles in Endothelium Reparation

MPs independently of direct cell-cell contacts with secreted proteins or diffusible soluble stimulatory factors secreted by antigen presenting cells [20].

\section{DEFINITION OF MICROPARTICLES}

MPs are large and very variable on their shapes and dimensions(predominantly 100-1000 nm) population of microvesicles, whichare shedding from plasma membranes of parent cells in response to cell activation, injury, and/or apoptosis [21, 22].Under normal physiological condition a phospholipid bilayer of plasma membrane of cells represented phosphatidylserine and phosphatidylethanoalamine in inner leaflets, whereas phosphatidylcholine and sphingomyelin represent in the external leaflets. The asymmetrical distribution of phospholipids in the plasma membrane is supported by activity of three major intracellularATP-dependent enzyme systems, i.e. flippase, floppase, and scramblase. Because aminophospholipids are negatively charged, but phospholipids exhibit neutral charge, the main role of intracellularenzyme systems is supporting electrochemical gradient. Both flippase and floppase belong to family of ATP-dependent phospholipid translocases.The flippasetranslocates phosphatidylserine and phosphatidylethanoalamine from the external leaflets to the inner one. The floppase transports phospholipids in the opposite direction. Finally, scramblase being to Ca2+-dependent enzyme system exhibits unspecifically ability of moving of phospholipids between both leaflets of plasma membrane [23].

Importantly, disappearing of the asymmetrical phospholipid distribution in the bilayer of the cell membrane is considered a clue for vesiculation and forming of MPs. Indeed, both processes of apoptosis or cell activation are required asymmetry in phospholipid distribution that leads to cytoskeleton modifications, membrane budding and MPs release. The mechanism of vesiculationclosely affects genome and may mediate by some triggers including inflammation [21], while in some cases there is a spontaneous release of MPs from stable cells or due to injury from necrotic cells or from mechanically damaged cells [17].

Recently MPs are considered a cargo for various molecules. Indeed, MPs carry proteins, RNA, micro-RNA, and DNA fragments from their cells of origin to other parts of the body via blood and other body fluids. Within last decade it has become to know that MPs would act as information transfer for target cells [16]. However, the difference between innate mechanisms affected the release of MPs from stable cells, activated cells or apoptotic cells is yet not fully investigated and requires more studies [24].

\section{ENDOTHELIAL CELL-DERIVED MPS}

Endothelial cells-derived MPs are released by inducer like angiotensin II, lipopolysaccharide, and hydrogen peroxide leading to the worsening of endothelial integrity, endothelial dysfunction, development and progression of microvascular inflammation. All these processes relate to atherosclerosis, thrombosis, heart failure and lead to major CV events. However, there are multiple physiological pathways for endothelial cells-derived MPs generation like NADPH oxidase derived endothelial ROS formation, Rho kinase pathway, and mitogen-activated protein kinases.

Endothelial cells release phenotypically and quantitatively distinct MPs in activation and apoptosis. As a result, MPs are sufficiently distinguished each other on their ability to contain some antigen presentation [22-24] and inner components, i.e. matrix metalloproteinases(MMP)-2, MMP-9, MT1-MMP, chromatin, active molecules (heat shock proteins), some hormones (angiotensin II), growth factors (transforming factor-beta) [24-27]. It is suggested that the epigenetic modification of the parent cells might directly impact on functionality of secreted MPs and their ability to influence various biological effects [28]. Indeed, the endothelial cell-derived MPsisolated from the serum of patients with diabetes mellitus, chronic kidney disease, heart failure and 
atherosclerosis are defective in induction of vascular relaxation, maturation of progenitor cells and endothelium repair [29-32]. As factors contributing in the response of the target cells after MP stimulation they could be pointed inflammatory cytokines (tumor necrosis factor-alpha, interleukin-[IL] 4, IL-17), glucose, advanced glycation end-products, uremic toxins, free DNA, products of lipid peroxidation [33]. Nonetheless, hypoxia-modified endothelial cell-derived MPs are able to carry reactive oxygen species and thereby may impair target cells by promoting apoptosis and oxidative stress [34]. They cannot be excluded the role of metabolomics-regulated microenvironments of target cells as a causative factor modifying the response after MPs' cooperation [35, 36]. It has been postulated that activation of p53 subunit, Akt/GSK-3beta and JAK2/STAT3signaling pathwaysare involved in the regulation of MPs' synthesis and that these molecular targets are under close control of various metabolites and intermediates, as well as epigenetics' mechanisms [37-40].Thus, secretome of endothelial cells included metabolites, proteins, intermediates, DNAs/, reactive oxygen radicals,active molecules, may probably modify and even alter a communicative ability of MPs secreted by endothelial cells [41-44].

\section{RELATION BETWEEN SECRETOME AND ENDOTHELIAL CELL FUNCTIONALITY}

Endothelial cell-derived MPs are not only delivery of intra-vesicular cargo and information, but they may directly modulate vascular functionautocrine and paracrine effects on target cells through surface interaction, and cellular fusion [45]. Subsequently, they have in vitroinvestigated that the MPs and other fractions of secretomemight mutually influence each another [9]. The final result of the interrelation may be shaping brand new biological components with irradiative abilities toward target cells [46, 47]. Finally, it has been suggested that enhancing of thetarget cell mobility and differentiation through MP production could be worse, inverted or even sufficiently abandoned [48]. Indeed, secretome of apoptotic peripheral blood cells may induce cytoprotection effect instead expected worsening of tissue remodeling in animal model of acute myocardial infarction [49-51]. Additionally, this effect is probably due to the activation of pro-survival signalling cascades in the cardiomyocytesand the increaseof homing of regenerative cellsthrough stimulationof metabolite modified MPs. Else, in clinical settings angiogenic early outgrowth endothelial progenitor cells have been reported to contribute to endothelial regeneration and to limit neointima formation after vascular injury through cooperation with metabolically modified MPs [52].

Thus, there is a large body of evidence regarding being of modifying effect of secretome components on MPs' ability for tissue regeneration or injury. Moreover, regenerative potency of apoptotic cell secretome was even higher than those in activated cells. However, new phenomenon opens serious perspective to clinical implementation of MPs as not just diagnostic tool with predictive possibilities, but as transfer system with therapeutic potentials [53,54].

Whether endothelial cell-derived MPs are capable to induce variable effects on target cells depending on proteomic of MPs or functional in nature of secretome is not fully understood. [55]. In fact, cross talk between some components of secretome including MPs might modulate delivering cargos of MPs through involving the intercellular signaling networks and thereby modify their regenerative and proliferative capabilities [56, 57]. Future investigations are requires to define the role of secretome in MPs' ability to produce different biological effects regarding endothelial repair, while recent studies are suggested the predominantly role of MPs' origin in this matter.

\section{CONCLUSION}

The endothelial cellsecretome has most commonly been investigated in pre-clinical settings as a source of regulating factors that are suitable for target cells. However, the interactionofdifferent components ofsecretome may modify the MPs' structure and functionality. It has been hypothesized that endothelial regeneration is under 
tight control of autocrine and paracrine mechanisms affecting not only parent endothelial cells, but also their secretome. Although there is the commonly used clinically validated biomarkers to identify endothelial injury and dysfunction, lack of endothelial reparation biomarkers, which are assessable in routine clinical practice, is crucial for an assay of probability to respond of the therapy. Through the pooling of data, discovery of the novel biomarkers of endothelial reparation could be improve our scoring of the patients requiringpersonalized care. The matter of metabolic modification of one is uncertain and requires more investigations in future. Greater understanding of the underlying mechanisms of impaired endothelial repair system could be a network of creating a novel platform for the evaluation of the novel treatment strategies.

\section{LIST OF ABBREVIATIONS}

Akt - RAC-alphaserine/threonine-specific protein kinase

DNA - deoxyribonucleic acid

$\mathrm{CV}$ - cardiovascular

GSK-3beta - Glycogen synthase kinase 3 beta

JAK - Janus kinase

IL - interleukin

MMP - matrix metalloproteinase

MPs - microparticles

NADPH - Nicotinamide adenine dinucleotide phosphate

RNA - ribonucleic acid

STAT3 - Signal transducer and activator of transcription

\section{REFERENCES}

1. Thulin Å, Christersson C, Alfredsson J, Siegbahn A. Circulating cell-derived microparticles as biomarkers in cardiovascular disease. Biomark Med. 2016; 10(9):1009-22.

2. Berezin AE, Kremzer AA, Martovitskaya YV, Berezina TA, Gromenko EA. Pattern of endothelial progenitor cells and apoptotic endothelial cell-derived microparticles in chronic heart failure patients with preserved and reduced left ventricular ejection fraction. EBioMedicine. 2016;4:86-94.

3. Berezin AE, Kremzer AA, Berezina TA, Martovitskaya YV. Pattern of circulating microparticles in chronic heart failure patients with metabolic syndrome: Relevance to neurohumoral and inflammatory activation. BBA Clin. 2015;4:69-75.

4. Berezin AE, Kremzer AA, Cammarota G, Zulli A, Petrovic D, Martell-Claros N, et al. Circulating endothelial-derived apoptotic microparticles and insulin resistance in non-diabetic patients with chronic heart failure. ClinChem Lab Med. 2016; 54(7):1259-67.

5. Berezin AE, Kremzer AA, Berezina TA, Martovitskaya Yu V.The pattern of circulating microparticles in patients with diabetes mellitus with asymptomatic atherosclerosis. ActaClinicaBelgica: International Journal of Clinical and Laboratory Medicine. 2016; DOI: 10.1080/17843286.2015.1110894

6. Berezin AE, Kremzer AA, Martovitskaya YV, Samura TA, Berezina TA, Zulli A, et al. The utility of biomarker 
The Modified Endothelial Cell-Derived Micro Particles in Endothelium Reparation

risk prediction score in patients with chronic heart failure. Int J ClinExp Med. 2015;8(10):18255-64.

7. Berezin AE, Kremzer AA, Martovitskaya YV, Samura TA, Berezina TA. The predictive role of circulating microparticles in patients with chronic heart failure. BBA Clin. 2014;3:18-24.

8. Berezin AE. Impaired Phenotype of Circulating Endothelial-Derived Microparticles: Novel Marker of Cardiovascular Risk. Journal of Cardiology and Therapy. 2015; 2(4): 273-278 doi:10.17554/j. issn.2309-6861.2015.02.77.

9. Beer L, Mildner M, Gyöngyösi M, Ankersmit HJ. Peripheral blood mononuclear cell secretome for tissue repair. Apoptosis. 2016;21(12):1336-1353.

10. Jeske WP, Walenga JM, Menapace B, Schwartz J, Bakhos M. Blood cell microparticles as biomarkers of hemostatic abnormalities in patients with implanted cardiac assist devices. Biomark Med. 2016;10(10):1095-1104.

11. Baron M, Boulanger CM, Staels B, Tailleux A. Cell-derived microparticles in atherosclerosis: biomarkers and targets for pharmacological modulation? J Cell Mol Med. 2012; 16(7):1365-76.

12. Berezin A, Zulli A, Kerrigan S, Petrovic D, Kruzliak P. Predictive role of circulating endothelial-derived microparticles in cardiovascular diseases. ClinBiochem. 2015;48(9):562-8.

13. Amabile N, Gurin AP, Leroyer A, Mallat Z, Nguyen C, Boddaert J. et al. Circulating endothelial microparticles are associated with vascular dysfunction in patients with end-stage renal failure. J Am SocNephrol. 2005;16:3381-8.

14. Pirro M, Schillaci G, Bagaglia F, Menecali C, Paltriccia R, Mannarino MR. et al. Microparticles derived from endothelial progenitor cells in patients at different cardiovascular risk. Atherosclerosis. 2008; 197: 757-67.

15. Yue WS, Lau KK, Siu CW, Wang M, Yan GH, Yiu KH, et al. Impact of glycemic control on circulating endothelial progenitor cells and arterial stiffness in patients with type 2 diabetes mellitus. CardiovascDiabetol. 2011;10:113.

16. Berezin A. The Clinical Utility of Circulating Microparticles' Measurement in Heart Failure Patients. J Vasc Med Surg. 2016; 4 (4): 275-284.

17. Berezin A. "Impaired immune phenotype" of endothelial cell-derived microparticles: the missed link between diabetes-related states and cardiovascular complications?Journal of Data Mining in Genomics \& Proteomics. 2016; 7(2): 195-197.

18. Nozaki T, Sugiyama S, Koga H, Sugamura K, Ohba K, Matsuzawa Y. et al. Significance of a multiple biomarkers strategy including endothelial dysfunction to improve risk stratification for cardiovascular events in patients at high risk for coronary heart disease. J Am CollCardiol. 2009;54:601-8

19. Mathivanan S, Ji H, Simpson RJ. Exosomes: extracellular organelles important in intercellular communication. J Proteomics. 2010;73:1907-1920.

20. Ostrowski M, Carmo NB, Krumeich S, Fanget I, Raposo G, Savina A, et al. Rab27a and Rab27b control different steps of the exosome secretion pathway. Nat Cell Biol. 2010;12:19-30.

21. Ullal AJ, Pisetsky DS, Reich C. Use of SYTO 13, a fluorescent dye binding nucleic acids, for the detection of microparticles in in vitro systems. Cytometry A. 2010;77:294-301. 
The Modified Endothelial Cell-Derived Micro Particles in Endothelium Reparation

22. Berezin AE. Metabolomics in Heart Failure Patients: Hype and Hope. Biomarkers J. 2016; 2 (3): e21-e23.

23. Berezin AE, Mokhnach RE.The promises, methodological discrepancies and pitfalls in measurement of cell-derived extracellular vesicles in diseases. J BiotechnolBiomater, 2016; 6 (2): 232-239 doi: 10.4172/2155-952X.1000232.

24. Simak J, Gelderman MP. Cell membrane microparticles in blood and blood products: potentially pathogenic agents and diagnostic markers. Transfus Med Rev. 2006;20:1-26.

25. Reich C, Pisetsky DS. The content of DNA and RNA in microparticles released by Jurkat and HL-60 cells undergoing in vitro apoptosis. Exp Cell Res. 2009;315:760-8.

26. Horstman LL, Jy W, Jimenez JJ, Ahn YS. Endothelial microparticles as markers of endothelial dysfunction. Front Biosci. 2004;9:1118-35.

27. Mayr M, Grainger D, Mayr U, Leroyer AS, Leseche G, Sidibe A. etal. Proteomics, metabolomics, andimmunomics on microparticles derived from human atherosclerotic plaques. CircCardiovasc Genet. 2009;2:379-88

28. Mause SF, Weber C. Microparticles: protagonists of a novel communication network for intercellular information exchange. Circ Res. 2010;107:1047-57.

29. Helmke A, von Vietinghoff S. Extracellular vesicles as mediators of vascular inflammation in kidney disease. World J Nephrol. 2016;5(2): 125-38.

30. Lu Y, Li L, Yan H, Su Q, Huang J, Fu C. Endothelial microparticles exert differential effects on functions of Th1 in patients with acute coronary syndrome. Int J Cardiol. 2013;168:5396-5404.

31. Angelot F, Seillès E, Biichlé S, Berda Y, Gaugler B, Plumas J, Chaperot L, Dignat-George F, Tiberghien P, Saas P, et al. Endothelial cell-derived microparticles induce plasmacytoid dendritic cell maturation: potential implications in inflammatory diseases. Haematologica. 2009;94:1502-1512.

32. Carpintero R, Gruaz L, Brandt KJ, Scanu A, Faille D, Combes V, Grau GE, Burger D. HDL interfere with the binding of $\mathrm{T}$ cell microparticles to human monocytes to inhibit pro-inflammatory cytokine production. PLoS One. 2010;5:e11869.

33. Scanu A, Molnarfi N, Brandt KJ, Gruaz L, Dayer JM, Burger D. Stimulated T cells generate microparticles, which mimic cellular contact activation of human monocytes: differential regulation of pro- and anti-inflammatory cytokine production by high-density lipoproteins. J Leukoc Biol. 2008;83:921-927.

34. Zhang $Q$, Shang M, Zhang M, Wang Y, Chen Y, Wu Y, et al. Microvesicles derived from hypoxia/reoxygenation-treated human umbilical vein endothelial cells promote apoptosis and oxidative stress in H9c2 cardiomyocytes. BMC Cell Biol. 2016 Jun 23;17(1):25. doi: 10.1186/s12860-016-0100-1.

35. Nomura S, Tandon NN, Nakamura T, Cone J, Fukuhara S, Kambayashi J. High-shear-stress-induced activation of platelets and microparticles enhances expression of cell adhesion molecules in THP-1 and endothelial cells. Atherosclerosis. 2001;158:277-287.

36. Boulanger CM, Scoazec A, Ebrahimian T, Henry P, Mathieu E, Tedgui A, Mallat Z. Circulating microparticles from patients with myocardial infarction cause endothelial dysfunction. Circulation. 2001;104:2649-2652.

37. Song JQ Teng X, Cai Y, Tang CS, Qi YF. Activation of Akt/GSK-3beta signaling pathway is involved in 
The Modified Endothelial Cell-Derived Micro Particles in Endothelium Reparation

intermedin(1-53) protection against myocardial apoptosis induced by ischemia/reperfusion. Apoptosis. 2009;14(11):1299-1307.

38. Jiang X, Guo CX, Zeng XJ, Li HH, Chen BX, Du FH. A soluble receptor for advanced glycation end-products inhibits myocardial apoptosis induced by ischemia/reperfusion via the JAK2/STAT3 pathway. Apoptosis. 2015;20(8):1033-1047.

39. Ou ZJ, Chang FJ, Luo D, Liao XL, Wang ZP, Zhang X, Xu YQ Ou SJ. Endothelium-derived microparticles inhibit angiogenesis in the heart and enhance the inhibitory effects of hypercholesterolemia on angiogenesis. Am J Physiology-endocrinology Metabolism. 2011;300(4):E661-E668.

40. Deregibus MC, Cantaluppi V, Calogero R, Lo Iacono M, Tetta C, Biancone L, et al. Endothelial progenitor cell derived microvesicles activate an angiogenic program in endothelial cells by a horizontal transfer of mRNA. Blood. 2007;110(7):2440-2448.

41. Eckers A, Haendeler J. Endothelial cells in health and disease. Antioxid Redox Signal. 2015;22(14):1209-1211.

42. Radecke CE, Warrick AE, Singh GD, Rogers JH, Simon SI, Armstrong EJ. Coronary artery endothelial cells and microparticles increase expression of VCAM-1 in myocardial infarction. ThrombHaemost. 2014;113(3):605-616.

43. Arderiu G, Peña E, Badimon L. Angiogenic Microvascular Endothelial Cells Release Microparticles Rich in Tissue Factor That Promotes Postischemic Collateral Vessel Formation. ArteriosclerThrombVasc Biol. 2015;35(2):348-357.

44. Zhang J, Ren J, Chen H, Geng Q. Inflammation induced-endothelial cells release angiogenesis associated-microRNAs into circulation by microparticles. Chin Med J (Engl) 2014;127(12):2212-2217ю

45. Curtis AM, Edelberg J, Jonas R, Rogers WT, Moore JS, Syed W, Mohler ER., 3rd Endothelialmicroparticles: sophisticated vesicles modulating vascular function. Vasc Med. 2013;18(4):204-214

46. Mukherjee P, Mani S. Methodologies to decipher the cell secretome. BiochimBiophysActa. 2013; 1834: 2226-2232.

47. Ankersmit HJ, Hoetzenecker K, Dietl W, Soleiman A, Horvat R, Wolfsberger M. et al. Irradiated cultured apoptotic peripheral blood mononuclear cells regenerate infarcted myocardium. Eur J Clin Invest. 2009; 39: 445-456.

48. Makridakis M, Roubelakis MG, Vlahou A. Stem cells: insights into the secretome. BiochimBiophysActa. 2013; 1834(11): 2380-4.

49. Lichtenauer M, Mildner M, Hoetzenecker K, Zimmermann M, Podesser BK, Sipos W, et al. Secretome of apoptotic peripheral blood cells (APOSEC) confers cytoprotection to cardiomyocytes and inhibits tissue remodelling after acute myocardial infarction: a preclinical study. Basic Res Cardiol. 2011; 106(6): 1283-97.

50. Lichtenauer M, Mildner M, Baumgartner A, Hasun M, Werba G, Beer L, et al. Intravenous and intramyocardial injection of apoptotic white blood cell suspensions prevents ventricular remodelling by increasing elastin expression in cardiac scar tissue after myocardial infarction. Basic Res Cardiol. 2011;106(4):645-55.

51. Lichtenauer M, Mildner M, Werba G, Beer L, Hoetzenecker K, Baumgartner A, et al. Anti-thymocyte globulin induces neoangiogenesis and preserves cardiac function after experimental myocardial infarction. PLoS One. 2012;7(12):e52101. 
The Modified Endothelial Cell-Derived Micro Particles in Endothelium Reparation

52. Mause SF, Ritzel E, Liehn EA, Hristov M, Bidzhekov K, Müller-Newen G, et al. Platelet microparticles enhance the vasoregenerative potential of angiogenic early outgrowth cells after vascular injury. Circulation. 2010;122(5): 495-506.

53. Vlassov AV, Magdaleno S, Setterquist R, Conrad R. Exosomes: current knowledge of their composition, biological functions, and diagnostic and therapeutic potentials. BiochimBiophysActa. 2012; 1820, 940-948.

54. Ankrum JA, Miranda OR, Ng KS, Sarkar D, Xu C, Karp JM. Engineering cells with intracellular agent-loaded microparticles to control cell phenotype. Nat Protoc. 2014;9(2):233-45.

55. Le Bihan MC, Bigot A, Jensen SS, Dennis JL, Rogowska-Wrzesinska A, Lainé J, et al. In-depth analysis of the secretome identifies three major independent secretory pathways in differentiating human myoblasts. J Proteomics. 2012; 77: 344-56.

56. Berezin A. Endothelial progenitor cells dysfunction and impaired tissue reparation: the missed link in diabetes mellitus development. Diabetes \& Metabolic Syndrome: Clinical Research \& Reviews. 2016 [ahead of print] Doi: 10.1016/j.dsx.2016.08.007.

57. Berezin A. Bone-Related Proteins as Markers in Vascular Remodeling / In.: V.R. Preedy (ed.), Biomarkers in Bone Disease: Methods, Discoveries and Applications, Switzerland, Springer, 2016. - 26p. DOI 10.1007/978-94-007-7745-3_4-1.

Citation: Alexander E. Berezin, Professor, MD, Ph.D., "The Modified Endothelial Cell-Derived Micro Particles in Endothelium Reparation". American Research Journal of Cardiovascular Diseases; 1(1); pp: 8-16

Copyright $@$ Alexander E. Berezin, Professor, MD, Ph.D., This is an open access article distributed under the Creative Commons Attribution License, which permits unrestricted use, distribution, and reproduction in any medium, provided the original work is properly cited. 